\title{
Expansión dispersa, ciudad difusa y transporte: el caso de Querétaro, México
}

Carlos Martner. Instituto Mexicano del Transporte, Querétaro, México.

RESUMEN | A partir de la discusión conceptual sobre las tendencias de concentración y dispersión espacial en las fases recientes de desarrollo capitalista y la transformación de las relaciones entre lo urbano y lo rural, se analiza el papel que desempeńan las redes de transporte en los nuevos patrones de ordenación del territorio de una ciudad intermedia mexicana (Querétaro), caracterizada por la expansión difusa de su zona metropolitana. Este proceso involucra un vínculo creciente con localidades rurales (microrregión Navajas-Galera), las mismas que han visto modificarse aceleradamente su entorno en los últimos quince años, por el asentamiento progresivo y discontinuo de actividades industriales y de servicios en el territorio. El método de análisis, basado en un enfoque estructural-sistémico, muestra el progresivo desvanecimiento de la división conceptual tajante establecida tradicionalmente entre el campo y la ciudad. Asimismo, constata que el desarrollo de los sistemas de transporte regional constituye un elemento estratégico de articulación espacial en esta nueva configuración territorial ampliada, donde la intensificación de la movilidad es sustantiva.

PALABRAS CLAVE | expansión urbana, relación campo-ciudad, transporte.

ABSTRACT | Based on the conceptual discussion on trends in spatial concentration and dispersion in the recent phase of capitalist development and the transformation of relations between urban and rural issues, this article discusses the role of transport networks in new spatial patterns of a Mexican intermediate city (Querétaro), characterized by the diffuse expansion of its metropolitan area. This process involves a growing link with rural localities (Navajas-Galera micro-region), which have witnessed the rapid modification of their environment in the past fifteen years by the progressive and discontinuous settlement of industrial and service activities in the territory. The method of analysis, based on a structural-systemic approach, shows the progressive disappearance of the sharp conceptual division traditionally established between the countryside and the city. It is also noted that the development of regional transport systems is a strategic element of spatial articulation in this new enlarged territorial configuration, where the intensification of mobility is substantive.

KEYWORDs | urban expansion, rural-urban relationship, transport.

Recibido el 23 de mayo de 2014, aprobado el 23 de octubre de 2014

E-mail: martner@imt.mx 


\section{Introducción}

Un tema recurrente en los análisis territoriales recientes es el de la dispersión y/o concentración de las aglomeraciones urbanas. El interés por tales materias proviene precisamente de las transformaciones en los patrones de organización del territorio, originadas en la reestructuración del capitalismo a nivel mundial desde las décadas finales del siglo $\mathrm{xx}$, procesos que han traído aparejados vaivenes constantes en las características de conformación de las zonas urbanas y rurales. Así, tan pronto se habla de tendencias de dispersión de las actividades y la población en el territorio como, en el momento siguiente, se están seńalando nuevas tendencias concentradoras y centralizadoras.

En las últimas dos décadas, la estructura urbano-regional de México ha sufrido enormes transformaciones socioterritoriales que están modificando rápidamente las actividades productivas, los empleos, las relaciones sociales, las formas culturales y de vida de miles de personas de escasos recursos, cuyo hábitat natural se ha trastocado de manera radical por un acelerado proceso de urbanización del campo. En general, se trata de regiones o territorios dinámicos, con crecimiento de nuevas actividades industriales y de servicios vinculadas a cadenas productivas globalizadas, cuya localización se viene dando mediante una creciente expansión urbana que se desdobla ya no solo sobre las periferias inmediatas de las ciudades, sino sobre un ámbito regional más extenso.

En efecto, en muchas ciudades económicamente dinámicas del país el proceso de expansión abarca un ámbito espacial mucho más amplio y poroso, donde no solo está incluido el paisaje urbano continuo, sino múltiples localidades rurales vinculadas fuertemente a la urbe. Esta configuración está siendo posible en buena medida por el desarrollo de la infraestructura y los sistemas de transporte regional, que articulan de manera inédita un ámbito territorial cada vez más extenso y complejo. Tal es el caso del entorno regional de la ciudad de Querétaro, México, donde hasta hace algunos años predominaban las actividades primarias propias de ámbitos rurales, pero con la inserción creciente de empresas del sector secundario y terciario vinculadas a procesos de internacionalización del capital, se está generado una significativa reestructuración territorial que propicia nuevos vínculos socioterritoriales y nuevas desigualdades regionales.

En este marco, la presente propuesta tiene por objetivo analizar el papel y relevancia de los sistemas de transporte en la transformación de las relaciones entre lo urbano y lo rural en la región de Querétaro, con especial énfasis en el análisis de la llamada microrregión Navajas-Galeras. Ubicada a 40 kilómetros de la ciudad de Querétaro, está constituida por un gran número de localidades rurales que han visto modificarse aceleradamente su entorno en los últimos quince ańos por el asentamiento progresivo de zonas industriales y, recientemente, por la construcción e inauguración del Aeropuerto Internacional de Querétaro (AIQ). Este vertiginoso cambio se produce bajo un contexto de expansión dispersa de la zona metropolitana de la Ciudad de Querétaro y de reorganización territorial sustentada en el cambio de las actividades económicas y en la conformación de un sistema de transporte rural-regional vinculado a un ámbito urbano crecientemente difuso. 
En la elaboración de este trabajo, se partió de la premisa de que el fenómeno urbano no puede ser cabalmente entendido sin incorporar en el análisis su articulación con el ámbito rural-regional inmediato. Conceptualmente esto implica que, en el nuevo marco de reorganización territorial, tiende a desdibujarse cada vez más la división tajante establecida tradicionalmente entre campo y ciudad. Lo que en última instancia están mostrando estas tendencias es la necesidad de revisar críticamente algunos esquemas conceptuales aceptados de manera generalizada en el análisis territorial, como la dicotomía rural-urbana o urbana-regional.

Para zanjar tales lagunas, se propuso un enfoque metodológico donde la unidad de análisis rebasa los límites del ámbito urbano o metropolitano y se abre a un ámbito de comprensión más amplia, el de los nuevos fenómenos de vinculación entre áreas rurales y urbanas. Esta perspectiva incorpora las modificaciones socioterritoriales propias de un modelo modernizador de inspiración neoclásica, que trae adosados procesos de fragmentación, apropiación desigual de los excedentes y exclusión de segmentos de la población que no logran asimilar o adaptarse a los recientes patrones socioeconómicos y culturales que demandan estas nuevas relaciones sociales. En otras palabras, a la luz de esta perspectiva, se revelaron nuevas formas de configuración territorial que exigen incluir en el análisis a los crecientes sectores sociales localizados fuera de los márgenes de la ciudad, pero que interactúan constantemente con ella, con sus diferenciaciones y nuevas desigualdades.

En este contexto, cabe señalar que existe escaso trabajo desarrollado sobre las modificaciones que producen los procesos de dispersión y concentración en los centros urbanos intermedios, como Querétaro. Menos consideración aún se ha tenido para el necesario análisis de ciertas condiciones generales para la producción, que tienen un papel crucial en la concentración y la dispersión territorial, como es el caso del transporte y las comunicaciones. Ello está ocurriendo especialmente en este periodo, en el cual la reconstitución del sistema capitalista a nivel mundial pasa por procesos de fuerte fragmentación territorial.

Ciertamente, la literatura al respecto se aboca principalmente al estudio de las metrópolis o los grandes centros urbanos, tanto en países centrales como periféricos; por lo tanto, poco se ha avanzado en establecer los cambios que estos procesos de dispersión y concentración generan en la relación campo-ciudad o, más precisamente, en la interacción entre ámbitos rurales y urbanos. El camino por recorrer es todavía más largo cuando se trata del análisis del rol central que las infraestructuras y los sistemas de transporte tienen en las tendencias recientes de crecimiento urbano-regional difuso.

Con miras a desarrollar lo anterior, el presente trabajo se ha estructurado en cuatro secciones, además de la introducción y las conclusiones. Así, en el segundo apartado, tras esta introducción, se reflexiona sobre las tendencias seculares y emergentes de concentración y dispersión territorial en las distintas fases del capitalismo. En particular se aborda el tema del proceso de concentración territorial bajo el modelo de sustitución de importaciones y posteriormente bajo el modelo actual de desregulación, apertura comercial y globalización.

En la tercera sección se profundiza en el análisis conceptual de las tendencias recientes de concentración y dispersión, rescatando las aportaciones de autores 
latinoamericanos y europeos que buscan explicar el fenómeno de la expansión dispersa y difusa de las zonas metropolitanas desde diversas perspectivas. En todas ellas, sin embargo, se evidencia la ausencia de estudios que revelen el rol estructurante que tienen sobre el territorio las infraestructuras y los sistemas de transporte, sin los cuales las expansiones más allá de los límites urbanos de las grandes zonas metropolitanas, pero también de las intermedias, no serían espacialmente viables.

En el apartado cuarto se aterrizan los conceptos previamente debatidos, al analizarse el papel de la configuración del sistema de transporte rural-regional en la expansión dispersa y difusa de Querétaro, con énfasis en el caso de la microrregión Navajas-Galera, cuya acelerada transformación genera relevantes cambios socioterritoriales. Los motivos y la intensidad de los viajes, los principales orígenes y destinos vinculados, muestran con gran nitidez los nuevos patrones de movilidad de los habitantes de comunidades rurales fuertemente articulados a las actividades urbanas por un eficaz sistema de transporte regional.

En el quinto capítulo se reflexiona sobre los dilemas actuales de la planeación urbano-regional, en un contexto donde los Estados cedieron muchos espacios al reducir el poder y atribuciones de la gestión de planes y programas de ordenación del territorio, frente a las actuaciones de los agentes u operadores inmobiliarios privados, es decir, frente a las decisiones del mercado.

Finalmente, se elaboraron unas conclusiones, ciertamente preliminares, donde se atisba que los sistemas de transporte regional se están convirtiendo en un elemento estratégico de articulación espacial para la nueva configuración territorial en la que se inserta la microrregión Navajas-Galeras, la misma que está fuertemente articulada al proceso de expansión territorial discontinuo, fragmentado y difuso de la ciudad y zona metropolitana de Querétaro. Sin duda este fragmento territorial experimenta una fuerte ebullición e intensa modificación socioterritorial, en la cual la intensificación de la movilidad de sus habitantes es un signo distintivo que habrá que analizar cada vez con mayor detalle.

\section{Tendencias seculares y emergentes de concentración y dispersión territorial}

La concentración de población y actividades productivas en constreñidos límites territoriales ha sido una tendencia histórica dentro del modo de producción capitalista. Las ventajas de la aglomeración han sido evidentes en la eficiencia del manejo de los procesos productivos, en la posibilidad de desarrollar una cooperación compleja dentro y entre las empresas manufactureras y en el necesario proceso de socialización de las fuerzas productivas, que ha sido fundamental para la producción, el intercambio y el consumo.

Sin embargo, la concentración territorial ha traído aparejada contradicciones que llevan a propiciar fuerzas contrarias, es decir, tendencias hacia la dispersión. Estas "desventajas de la aglomeración" provienen en buena medida de la anarquía que genera, en el crecimiento de las ciudades, el carácter privado de la propiedad de los medios de producción y de la apropiación de la producción social y, con ello, el carácter individual de las decisiones de apropiación del territorio y de la producción de objetos inmobiliarios (Pradilla, 1984). 
De esta forma, se puede decir que la concentración es una vieja tendencia en la organización del territorio, la cual a menudo aparece asociada, estrecha y contradictoriamente, a tendencias hacia la dispersión, a las cuales ha controlado y subordinado. En general, en el desarrollo del capitalismo, tanto en países centrales como en los periféricos, la concentración territorial de la población y de las actividades económicas ha sido una tendencia predominante. Esto no excluye el hecho de que en algunos periodos de crisis y reestructuración las tendencias centrífugas cobrasen temporalmente un papel protagónico en la organización territorial de los países latinoamericanos.

De acuerdo con los análisis de Pradilla (1984), históricamente la concentración y la dispersión son viejas tendencias dentro del desarrollo del capitalismo; por lo tanto, nada nuevo se descubre en tal sentido. Sin embargo, lo que sí se ha modificado a través de las diferentes fases de desarrollo del sistema es la forma, las características, las cantidades y las cualidades en que se manifiestan la concentración y la dispersión territorial y los efectos que tienen en el funcionamiento del modelo o fase de acumulación en turno. En este contexto, sí es posible hablar de nuevas tendencias en los procesos de organización del territorio.

En años recientes, con la crisis del modelo y la posterior reestructuración capitalista, basada en una creciente internacionalización de los procesos productivos apoyados en nuevas tecnologías y en una nueva división internacional del trabajo, se han modificado notablemente las tendencias de concentración territorial. En América Latina, el agotamiento del modelo de acumulación, llamado "fordista" por autores europeos (Leborgne \& Lipietz, 1990), corresponde más bien a la crisis terminal del modelo de sustitución de importaciones. Este modelo buscó, desde los años cuarenta, fortalecer el desarrollo del capitalismo en los países del subcontinente mediante la conformación de la industria nacional y el fortalecimiento del mercado interno.

\section{El proceso de concentración territorial bajo el modelo de sustitución de importaciones}

En el modelo de sustitución de importaciones fue evidente el predominio de los procesos de concentración económica y demográfica sobre el territorio. La nueva industria, volcada sobre el mercado interno, privilegió su asentamiento en los centros urbanos históricamente más importantes donde, por lo demás, se concentraban lo primordial de las condiciones generales para la producción y el intercambio y los principales mercados del país. El asentamiento industrial, junto con el deterioro del sector agrícola (en buena parte, precapitalista), propició concentraciones, principalmente en las capitales de los países latinoamericanos.

La paulatina penetración de empresas transnacionales durante los años sesenta, cuando el modelo de sustitución de importaciones empezaba a mostrar signos de agotamiento, no modificó en nada las tendencias concentradoras de las principales áreas urbanas en los países latinoamericanos. Por el contrario, como el ámbito de acción de estas empresas en ese momento era el mercado interno, con su localización se reforzaron las tendencias centrípetas, a excepción de algunos enclaves mineros o agropecuarios vinculados principalmente con la extracción o producción de materias primas para la exportación. 
En todo caso, en esa fase no dejaron de existir ciertas fuerzas centrífugas en la organización territorial de las grandes urbes. Estas se produjeron por la evidencia de ciertas desventajas que mostraron los grandes conglomerados en formación, aunque tal dispersión se dio dentro de los límites de las zonas urbanas ampliadas. Los propios efectos de la aglomeración conducen a la dispersión (Pradilla, 1984). Pero en esa época se trató de una dispersión muy acotada e inserta en la concentración urbana. Se trató, sobre todo, de parques industriales ubicados en la periferia de las grandes ciudades, de zonas habitacionales promovidas por el Estado en márgenes urbanos, donde la presión de las rentas del suelo era menor; se trató también de las incipientes invasiones de terrenos de poco valor en la periferia urbana por migrantes pobres del campo, los cuales vinieron a reforzar un creciente ejército de subempleados y desempleados, y que solo de esa forma pudieron acceder a un terreno y a una vivienda autoconstruida en la ciudad. Estos grupos sociales "desarrollan individual o colectivamente la dispersión" (Pradilla, 1984, p. 481).

A esta dispersión restringida contribuyó también el capital inmobiliario, con la gestación de nuevos desarrollos habitacionales y comerciales en zonas selectas de la periferia, donde comenzaron a valorizarse condiciones ambientales y geográficas que se habían perdido en los centros de las ciudades. Finalmente, todos estos procesos no abarcaban más allá de los límites en expansión de la propia ciudad. Se trata, pues, de una dispersión dentro de la concentración urbana, dentro de sus márgenes.

En México, las acciones más notables en materia de desconcentración fueron impulsadas por el Estado a través de la política de creación de polos de desarrollo, consistente en la localización de empresas paraestatales en ciudades intermedias o menores. Se trató de iniciativas basadas en programas de estímulos para la creación de parques industriales en varias entidades, que tuvieron lugar durante los años sesenta y setenta, cuando se hicieron más evidentes algunas deseconomías de aglomeración. Sin embargo, el efecto de tales políticas fue muy restringido mientras se mantuvo el modelo económico que privilegiaba la producción para el mercado interno y la protección frente al exterior. Solo después de la crisis del modelo de acumulación y su posterior reestructuración, algunas de las ciudades menores que recibieron los beneficios de aquellas políticas desconcentradoras han alcanzado dinámicos procesos económico-demográficos y están produciendo en la actualidad nuevas tendencias de ordenación territorial.

En efecto, la reestructuración capitalista produce una modificación cualitativa en los procesos de concentración y dispersión en el territorio. La crisis final del patrón de acumulación fordista en los países centrales y del modelo de sustitución de importaciones en América Latina provocó un fuerte declive en centros urbanos de densa industrialización en el periodo previo, así como "la emergencia de nuevas áreas capaces de atraer o generar inversiones en espacios tradicionalmente calificados como periféricos" (Méndez, 1994, p. 4). Así, desde mediados de los setenta, hasta buena parte de la década de los ochenta, se pudieron observar "múltiples evidencias sobre la detención del crecimiento industrial metropolitano y la emergencia de movimientos desconcentradores en favor de ciudades medias y pequeñas" (Méndez, 1994, p. 4). La desindustrialización de las grandes ciudades fue un tema recurrente durante los años ochenta en América Latina; pero también lo fue el de la 
emergencia de nuevas regiones que parecerían acoplarse de manera dinámica a los cambios en el modelo económico.

\section{La concentración territorial bajo el modelo} de aperturacomercial y globalización

Cualquier cambio importante en el proceso o la forma de acumulación de capital necesariamente provoca turbulencias y modificaciones en los patrones de concentración urbana y territorial. La implantación del llamado modelo neoliberal, que abrió ampliamente las fronteras de los países latinoamericanos a los capitales y mercancías internacionales, que desreguló la economía nacional, que privatizó las empresas paraestatales, que redujo la participación del Estado, no solo en los procesos económicos y las políticas públicas de bienestar social, sino también en aquellas abocadas a la planeación u ordenación del territorio, generó una mutación en las tendencias concentradoras previas y, en una primera fase, dio pie a importantes tendencias de dispersión territorial. Algunas de las llamadas ciudades medias o centros urbanos intermedios mostraron dinámicas demográficas y económicas mayores en términos relativos que las de las grandes urbes, donde bajo los efectos de la crisis y del fuerte proceso de desindustrialización en curso, muchas de las empresas surgidas al amparo del modelo de sustitución de importaciones sufrían un fuerte colapso. Los trabajos de Aguilar (1996), Álvarez (2011), Anzaldo (2006), Graizbord (1992) y Sánchez y Propin (2001), entre otros, entregan copiosa información sobre esta tendencia, vigente desde los años noventa en México. Entre las ciudades intermedias más dinámicas destacan las del norte, el occidente y el Bajío, incluida la ciudad de Querétaro, que desde esa década muestra tasas de crecimiento poblacional y económico notablemente superiores a las de las grandes zonas metropolitanas del país.

La orientación de la producción hacia el mercado externo actuó como fuerza dispersora en los patrones de localización de la nueva industrialización, que buscaba acoplarse al modelo económico emergente. La cercanía a los principales mercados internos dejó de ser un factor determinante en los criterios de localización de las empresas. Se valoraron elementos como ambientes sociales poco conflictivos, con escasa organización de la fuerza de trabajo y, por lo tanto, muy propicios para la flexibilización de las relaciones laborales requeridas por el nuevo modelo de acumulación, cuyos mercados son más segmentados e inestables (Hiernaux, 1993). Se consideró también la dotación de infraestructura, sobre todo de comunicaciones y transportes, para enlazarse rápidamente con los puntos fronterizos. Así, en los primeros años de la crisis y del proceso de reconversión de la estructura productiva, la "detención del crecimiento industrial de la gran ciudad resultó convergente con una dinamización selectiva de algunas áreas (antes consideradas) periféricas" (Méndez, 1994, p. 5).

El incipiente proceso de dispersión señalado fue apoyado y sostenido fuertemente por el cambio tecnológico indisolublemente ligado a la reestructuración capitalista reciente. La innovación tecnológica no se da solo por la introducción de nuevos equipos y máquinas, sino que está asociada también a una transformación profunda en la organización de los procesos productivos. En estas nuevas formas organizativas destaca la fragmentación de la producción, que implica, entre otras 
cosas, la búsqueda de la localización espacial óptima para cada fase de elaboración del producto. Tales métodos de producción requieren de un fuerte apoyo de condiciones generales para la producción y, en especial, de las nuevas tecnologías en comunicaciones y transportes, para que coordinen los procesos y posibiliten su realización incluso a larga distancia (Castells, 1997; Martner, 1996; Sassen, 1991).

En este tenor, la fragmentación de la producción lleva implícita una concepción de desconcentración, de dispersión; sin embargo, comporta también un elemento de centralización de la toma de decisiones en el control y la dirección de los procesos a larga distancia desde lugares o espacios territoriales selectos. De esta manera, lo que parecía todavía a principios de la década de los ochenta "el fin de las tendencias centrípetas dominantes en el periodo de industrialización y su sustitución por movimientos de carácter centrífugo, apoyados por las mejoras técnicas en el plano de las comunicaciones" (Méndez, 1994, p. 5), no resultó ser un proceso tan absoluto. En efecto, en la década de los noventa, las grandes ciudades, tanto en países centrales como periféricos, después de largos procesos de reconversión, empezaron a mostrar signos de recuperación económica, al menos en términos de las actividades de mayor valor agregado y contenido tecnológico.

Así es como, dentro del proceso de fragmentación de la producción, las grandes ciudades han sido lugares importantes para la localización de las sedes administrativas y organizativas de las empresas. La presencia de los mercados financieros en las grandes urbes es otro elemento de atracción para las actividades de gestión de las empresas. También ha aparecido una serie de "tareas pre y post-producción, en detrimento de las de fábrica-taller, como resultado de la creciente incorporación de las tecnologías de la información” (Méndez, 1994, p. 9), tareas que tienden a ser englobadas dentro del concepto de terciarización industrial. Este fenómeno es especialmente visible en zonas centrales de las grandes ciudades, donde aparecen las llamadas oficinas industriales.

Cabe señalar que no solo las fases de alto valor de la producción industrial parecen concentrarse en las metrópolis, sino también las principales actividades relacionadas al intercambio, entre las que destacan las bolsas de valores, las casas de bolsas, los bancos, así como los centros logísticos de distribución, las terminales intermodales y las centrales de abasto, entre otros. Ni qué decir del vasto campo de los servicios profesionales que se han desarrollado en las ciudades, algunos de los cuales muestran alto grado de especialización.

Estos patrones recientes de organización territorial parecieran señalarnos que las tendencias desconcentradoras fueron de corto aliento y que se regresa al predominio de la tendencia concentradora característica del periodo previo a la crisis. Castells (1997), por ejemplo, señala que actualmente las grandes ciudades son las que se constituyen en los nudos determinantes del nuevo modelo de crecimiento, con su concentración y articulación de actividades direccionales, de empresas innovadoras y sistemas de gestión, decisión y producción de conocimiento. En tal rubro caben aquellos ámbitos urbanos o metropolitanos dinámicos localizados en lo que Saskia Sassen (2003) llama el Sur Global. Lo cierto es que, bajo esta perspectiva, se da cuenta de una nueva etapa de centralización productiva, en el que se condensan, desde el punto de vista territorial, tanto la concentración como la dispersión. 


\section{Tendencias recientes de concentración-dispersión territorial y sistemas de transporte}

Si bien es cierto que desde la década de los noventa del siglo pasado parecen haberse reactivado las tendencias concentradoras en torno a las grandes urbes, el proceso en curso presenta características cualitativamente diferentes al que se dio durante el predominio del régimen de acumulación fordista o del modelo de sustitución de importaciones en América Latina.

En primer término, la concentración aparece ahora como un proceso más amplio a nivel territorial. Incluye no solo terreno edificado, sino también grandes extensiones de suelo rural. En medio de esas amplias zonas quedan insertados tanto poblados campesinos como ciudades menores o intermedias. En estudios acerca de ciudades intermedias latinoamericanas se ha constatado que se produce un fenómeno similar al de las grandes metrópolis, es decir, tienden a involucrar extensiones amplias de zonas no urbanas entre las cuales se insertan localidades y poblados menores (Espino, 1995). Así, bajo estas relaciones múltiples parece estrecho colocar las zonas urbanas intermedias solo como nuevas concentraciones subordinadas a metrópolis. Parecería que eso es solo parte del proceso, porque las ciudades intermedias también crean y reproducen centralidad y dispersión no solo hacia sus franjas periurbanas, sino también hacia los ámbitos rurales.

Además, según señala Álvarez (2011):

Los nuevos cambios en la dinámica de crecimiento urbano en México desde 1990 indican que, por un lado, las grandes zonas metropolitanas disminuyen su crecimiento de población a favor de las localidades urbanas localizadas en su área de influencia, y por otro lado, las ciudades medias o intermedias se caracterizan por ser los nuevos centros urbanos de mayor crecimiento demográfico (Graizbord, 1992; Aguilar, 1996; Sánchez, 2001; Anzaldo, 2006), así como poseer una mayor atracción para la población migrante que las zonas metropolitanas, como tradicionalmente se había presentado. Este patrón de urbanización se ha mantenido hasta principios del siglo Xxi. (pp. 92-93)

En este escenario, las nuevas tendencias de organización territorial en México y América Latina han planteado encrucijadas teóricas y metodológicas aún no resueltas por los estudiosos del tema. Desde la década de los ochenta parece evidente que divisiones conceptuales tradicionales, utilizadas por diferentes escuelas del pensamiento regional y territorial, como las establecidas entre campo y ciudad (Singer, 1977) o entre lo rural y lo urbano (Lefebvre, 1976), pierden efectividad en la interpretación de los fenómenos recientes.

Las carencias conceptuales para interpretar las modificaciones económicas, sociales y espaciales propiciaron la aparición de nuevos aportes latinoamericanos a partir de los años ochenta. Los esfuerzos más destacados y consistentes en este sentido están representados por autores que introducen un enfoque sistémico al análisis del territorio. Al respecto, cabe señalar que, a diferencia de la corriente sistémica europea o estadounidense, que es predominantemente funcionalista -es decir, que se define por elementos cuantitativos de validez general, como "la posición de 
las ciudades en el espacio (distancia entre ellas); el número de ciudades de cada tamaño que hay en el sistema; las complementariedades funcionales entre ellas a nivel industrial; la jerarquía de lugares centrales comerciales" (Racionero, 1978, p. 16)-, el enfoque sistémico de buena parte de los estudiosos latinoamericanos de los ochenta y noventa es de tipo estructuralista (Yocelevzky, 1999). Es decir, aparece vinculado a determinaciones históricas, económicas, sociales y culturales de los territorios en cuestión (Palacios, 1983). En este sentido son notables los trabajos de De Mattos (1983), sobre Chile y México, con su planteamiento sobre los subsistemas espaciales centrales y periféricos que articulan y definen el sistema nacional. Analiza al respecto el papel de los principales actores sociales en la conformación de estos subsistemas, y señala los problemas estructurales que enfrentan los subsistemas periféricos para insertarse en los circuitos de acumulación de capital y en las actividades económicas capitalistas, generalmente controlados en los subsistemas centrales.

En la misma época, Alejandro Rofman (1984) desarrolla, en Argentina, el estudio de los subsistemas espaciales a partir de la definición y delimitación de los circuitos regionales de acumulación. Con este planteamiento, el autor también rompe con conceptualizaciones regionales y territoriales previas que separaban el análisis de lo rural y lo urbano. Los subsistemas espaciales, en este caso, se despliegan en el territorio sobrepasando las ciudades y el ámbito regional mismo. Para Rofman, aunque los agentes sociales actúen en un marco regional previamente delimitado, "el proceso productivo escapa a sus límites y comprende a otros agentes situados fuera de ese subespacio" (p. 43). Este autor reconoce los antecedentes teóricos de su planteamiento sistémico en el enfoque histórico-estructural, no en la escuela funcionalista.

Otro gran aporte latinoamericano, desde esta perspectiva estructural sistémica (Yocelevzky, 1999), es el de los trabajos de José Luis Coraggio, basados en sus experiencias en Nicaragua y Ecuador. En su obra Los complejos territoriales dentro del contexto de los subsistemas de producción y circulación (1987), Coraggio incorpora de manera explícita la cuestión de la circulación física (y, en este sentido, de la infraestructura de enlace entre espacios urbanos y regionales) al análisis territorial. Esto le permitió acercarse más claramente a la determinación de ámbitos territoriales específicos, ubicando en el espacio tanto a los agentes como las relaciones entre ellos. Afirma así que "la producción solo puede ser vinculada significativamente con las formas espaciales de una sociedad si se la investiga incorporando las condiciones y procesos de su reproducción, lo que requiere recuperar su unidad orgánica con la circulación" (p. 18).

En la década de los noventa continuaron apareciendo trabajos interesantes sobre el tema, que buscaban nuevas concepciones de análisis. Tal es el caso de los trabajos de Ramírez y Pradilla (1993) en México, donde desarrollaron el concepto de sistemas territoriales extensos. Estos sistemas, señalan los autores, se caracterizan por ser desiguales, fragmentados, con formas productivas y organizativas combinadas, donde coexisten desde prácticas tradicionales precapitalistas hasta desarrollos tecnológicos de punta en contextos ampliamente internacionalizados (o, si se quiere, globalizados) de acumulación de capital.

No obstante tales nuevas perspectivas, no deja de llamar la atención la casi total ausencia del factor transporte en los estudios urbano-regionales de ese periodo. En 
efecto, los avances en este tema se produjeron sobre todo en el campo de la ingeniería, con enfoques técnicos que buscaban proporcionar mayor funcionalidad y eficiencia a las crecientes redes de transporte urbano (Cal y Mayor, 1994). Desde la perspectiva del análisis territorial, en Latinoamérica escasamente encontramos una clara referencia a la relevancia de los sistemas de transporte en los procesos de expansión urbana y metropolitana, más allá de los trabajos del investigador brasileño Lucio Kowarick (1992), quien para entonces planteaba que la periferización de las ciudades no pudo haber ocurrido sin la previa alteración en los sistemas de transporte. Ahora bien, la periferización de las ciudades en las décadas previas (desde los sesenta a los noventa del siglo $\mathrm{xx}$ ) consistió, principalmente, en la expansión constante de las franjas periurbanas hacia los márgenes de la ciudad, en tanto que, actualmente, este proceso parece incluir vastas áreas de territorio en donde se insertan, de manera discontinua, localidades pequeñas semirrurales y rurales dispersas en el territorio.

De esta manera, en la actualidad es insuficiente hablar solo de la periferización a la que hace referencia Kowarick (1992), puesto que más bien se asiste a un proceso de desdoblamiento del ámbito urbano sobre el rural. Así considerado, la alteración de los sistemas de transporte incluye no solo la expansión de las redes de transporte urbano de pasajeros. También comprende la conformación de sistemas regionales de transporte para la movilización de crecientes contingentes de población, generalmente de bajos ingresos, que tienen su residencia no en la periferia urbana sino en localidades rurales, y que se dirigen cotidianamente a una ciudad mayor. Esto implica, como se verá en el caso de Querétaro, no solo la expansión o ampliación de las redes de transporte urbano, sino la aparición de sistemas de transporte de tipo suburbano y/o regional, con sus propias terminales, redes y frecuencias de servicio que articulan las localidades rurales con el centro urbano mayor y sus sistemas de transporte urbano. En otras palabras, articulan la dispersión de las comunidades rurales con un ámbito urbano cada vez más expandido y fragmentado sobre el territorio.

$\mathrm{Al}$ respecto, en la primera década del siglo XXI, se hace constante la aparición de nuevos términos que buscan explicar en fenómeno territorial en curso, caracterizado por el desdibujamiento progresivo de los contornos previamente tan bien establecidos entre lo rural y lo urbano. En efecto, para definir la novedad de estos procesos de expansión dispersa de la ciudad sobre los ámbitos rurales, ha surgido una serie de términos, como periurbanización o rururbanización, que

tienen el problema de no tener acepciones unánimemente aceptadas y ser utilizados con acepciones distintas según los autores, con lo que la confusión terminológica es patente. El espacio periurbano, a nuestro entender, es aquél situado en la periferia de la ciudad, que era eminentemente rural, pero que ha sufrido transformaciones profundas, tanto en el plano económico, como el demográfico y el social. El asentamiento de personas procedentes de la ciudad en estos lugares los convierte en espacios de carácter residencial, aunque estas gentes siguen trabajando en la ciudad, lo que hace que se produzcan cambios formales en el hábitat y en las comunicaciones. Así, este espacio pasa a tener numerosos usos -residencial, industrial, de ocio, agrícola, etc. (Formigo \& Aldrey, 2005, p. 317) 
Por tanto, el término "periurbanización” o difusión dispersa del crecimiento urbano sobre ámbitos rurales define un nuevo proceso de ocupación del espacio en las proximidades de las ciudades. La "rurubanización", por su parte, tiene una connotación más limitada, en la medida en que alude básicamente a aquel espacio en el que se mezclan los paisajes urbanos y rurales, yuxtaponiéndose y compitiendo por esas áreas (Fernández, 2003). De esta manera, la franja periurbana propia de la concepción de una ciudad crecientemente difusa, dispersa y fragmentada, se presenta como un espacio donde se produce una yuxtaposición de áreas construidas ex novo, el hábitat rural preexistente, polígonos industriales, espacios agrarios, vías de comunicación y lugares de ocio. Así, la ciudad entendida como tradicionalmente se hacía entra en crisis, y ahora habría que sustituir el concepto de ciudad como núcleo principal aislado, por el de ciudad difusa o ciudad región, lo cual supone la consideración tanto de la población central como la de toda la orla periurbana intensamente conectada con ella por flujos cotidianos, ya sea laborales o de otra índole (Formigo \& Aldrey, 2005).

Cabe señalar que, en la última década, la bibliografía acerca de las ciudades latinoamericanas ha puesto énfasis en los procesos de fragmentación y/o expansión difusa de las principales metrópolis de la región. En este sentido pueden situarse los destacados trabajos de Borsdorff (2003), Cariola y Lacabana (2001), De Mattos (2006 y 2010), Hidalgo (2004), Janoshka (2006), Link (2008), Parnreiter (2003), Vidal-Koppman (2009), entre otros. De acuerdo con Jirón y Mansilla (2014), las investigaciones recientes sobre el tema muestran básicamente
dos líneas de análisis respecto del proceso de fragmentación urbana: la primera relacionada con las discontinuidades en el proceso de expansión urbana respecto de su trama; y la segunda, ligada a procesos de desigualdad social y barreras materiales o inmateriales de esta fragmentación. (p. 8)

No obstante, poco se ha avanzado en el análisis de la movilidad y el desarrollo de los sistemas de transporte como elemento relevante, e incluso clave, para comprender la creciente fragmentación espacio-temporal de las ciudades grandes e intermedias de la actualidad; o, si se quiere plantear desde otra perspectiva, para comprender el papel articulador (o desarticulador, según sea el caso) del transporte sobre la ciudad difusa y fragmentada de hoy. Precisamente, en el siguiente inciso se analiza el rol del sistema de transporte regional de Querétaro como un articulador territorial de la movilidad de las comunidades rurales hacia un ámbito urbano cada vez más expandido y fragmentado.

En este contexto se plantea, a manera de hipótesis, que la transformación acelerada del área de estudio (la microrregión Navajas-Galera) se da en un contexto de expansión de la zona metropolitana de la Ciudad de Querétaro y de una reorganización territorial a nivel regional. Tal reorganización se sustenta en el cambio de las actividades económicas y en la conformación de mecanismos de movilidad y accesibilidad basados en el desarrollo de sistemas de transporte regional articulados al ámbito urbano. Esto último constituye un elemento central de las recientes tendencias de expansión dispersa, fragmentada o difusa de ámbitos urbanos en ciudades intermedias, cuyo dinamismo económico y socioterritorial, asociado a las posibilidades tecnológicas para el desplazamiento físico constante de personas y 
mercancías, ha permitido desdoblar, sobre vastos espacios eminentemente rurales, las actividades secundarias y terciarias tradicionalmente asociadas a las ciudades. De esta forma, el papel de la movilidad de la población en una nueva territorialidad donde la dispersión geográfica se ha ampliado, tiene que ver con las características propias del actual modelo de desarrollo, el cual ha privilegiado una suerte de ordenación del territorio por el mercado, por sobre la planeación urbano-regional de tipo indicativa utilizada comúnmente en el periodo previo de sustitución de importaciones (De Mattos, 2010). En todo caso, la temática propuesta tiene un amplio margen para el análisis desde perspectivas tanto conceptuales como empíricas, y aquí se busca hacer contribuciones iniciales en ambas vertientes.

\section{Expansión dispersa y desarrollo de sistemas de transporte en torno a Querétaro: el caso de la microrregión Navajas-Galera}

\section{Transformación regional acelerada}

La configuración socioterritorial del entorno regional y rural de Querétaro se ha transformado sustancialmente con el emplazamiento de parques industriales dispersos en un espacio eminentemente rural, y la construcción (2005) del Aeropuerto Internacional de Querétaro (AIQ) en la extensa área llamada microrregión NavajasGaleras, que se ubica entre los municipios de El Marqués y Colón, al este de la Zona Metropolitana de Querétaro (figura 1). Dicha microrregión se localiza en promedio a 40 kilómetros de la ciudad de Querétaro, en una planicie dedicada durante décadas al desarrollo agropecuario, actividad que hoy en día se encuentra en franco retroceso. Desde la perspectiva de los asentamientos humanos, la zona se compone de dieciocho localidades eminentemente rurales, de las cuales trece se localizan en el municipio de El Marqués y las cinco restantes en el municipio de Colón.

En dos décadas, la microrregión Navajas-Galeras experimentó una transformación significativa en sus actividades productivas y en su dinámica poblacional. Así, de ser eminentemente agrícola y ganadera, ha ido incrementando gradualmente sus actividades industriales y de servicios, aun cuando las actividades primarias conservan alguna relevancia en la economía local, debido a la fertilidad de sus suelos y a la progresiva tecnificación de los procesos productivos agropecuarios.

Desde mediados de la década de los noventa, en la zona de estudio se han ubicado, de manera dispersa en un entorno eminentemente rural, al menos cuatro parques industriales (el Parque Bernardo Quintana-Finsa, el O’Donell Aeropuerto, el Marqués y el Parque Aeroespacial), donde se asientan cerca de setenta empresas de diversos sectores o ramas industriales, entre las que destacan: productos metálicos y autopartes, la aeronáutica, la eléctrica y electrónica, la de alimentos y bebidas y, de manera muy importante, la de servicios a la industria (centros de distribución, almacenes, empresas de transporte de mercancías, etcétera). 
FIGURA I | Zona Metropolitana de Querétaro y microrregión Navajas-Galeras

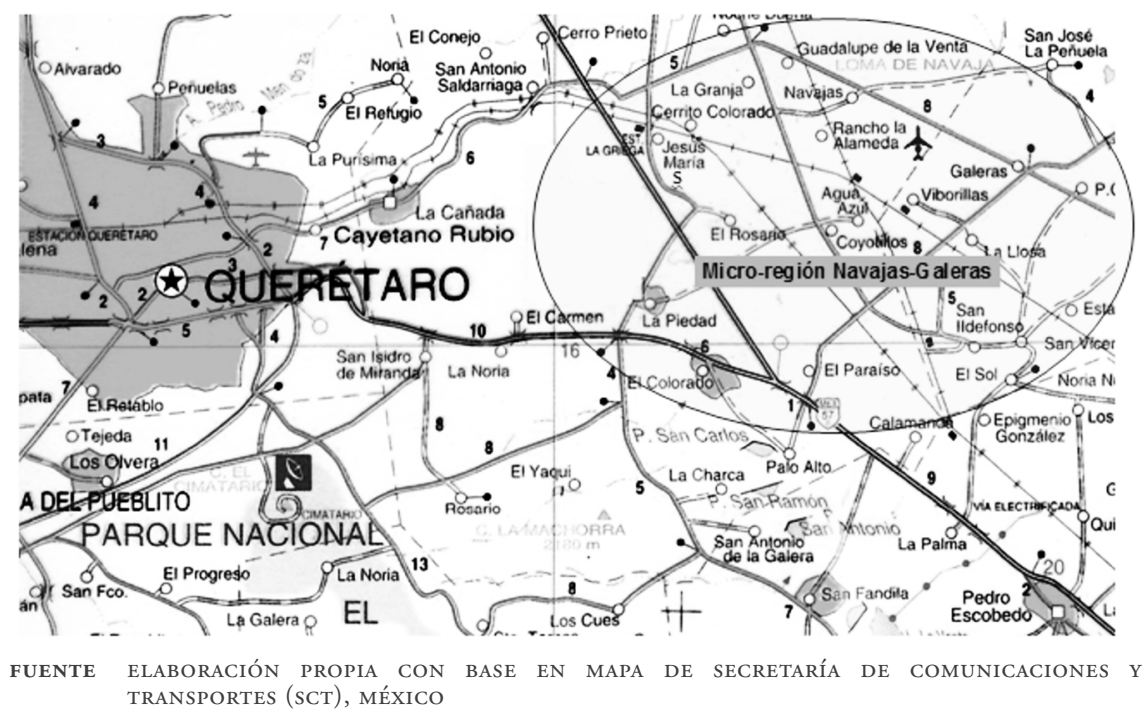

Cabe señalar que, de acuerdo con los estudios de González y Nieto (2007) y González (2012), en la zona no existe una clara especialización industrial y la mayoría de las empresas son eslabones de cadenas productivas globalizadas. Ello permite sostener que las relaciones interindustriales en la microrregión son escasas, por lo que, en estricto sentido, no estaríamos en presencia de clusters industriales. No obstante, después de la inauguración y entrada en operación del Aeropuerto Internacional de Querétaro, el sector gubernamental (el Gobierno Estatal, con apoyo del Federal), en la búsqueda de potenciar esta infraestructura e impulsar el desarrollo regional productivo, ha elaborado políticas y programas para crear un cluster aeroespacial en la región. Se está propiciando, de esta forma, la localización de nuevas plantas proveedoras de primer y segundo nivel, así como de servicios especializados de ingeniería, de investigación y desarrollo, de formación técnica y universitaria especializada, a fin de apoyar los procesos de clusterización en esta rama.

En todo caso, y para los efectos de este trabajo, es claro que la industrialización de la microrregión Navajas-Galeras, ubicada en los municipios de El Marqués y Colón del Estado de Querétaro, propició la modificación de las actividades de su población y las características de sus localidades. En 1990, el 38\% y el 32\% de la población económicamente activa (PEA) de los municipios de Colón y El Marqués, respectivamente, se ocupaba en el sector primario; el $36 \%$ y el $42 \%$ laboraba en el sector secundario, y el $25 \%$ y el $24 \%$ en el sector terciario. En el año 2010, cuando el Estado de Querétaro se terciarizaba más en sus actividades, Colón y El Marqués mantuvieron una creciente estructura ocupacional industrial (40\% y 43\% de la PEA, respectivamente), asociada a un sector terciario en claro ascenso (36\% y $39 \%$, respectivamente) y un primario en retroceso (24\% y $18 \%$ de la PEA municipal, respectivamente). Este patrón de actividades socioeconómicas contrasta con 
el tipo de localidad de residencia de los habitantes de la microrregión. En efecto, de acuerdo con el censo del año 2010, el 68\% de la población de Colón y el 51\% de la población de El Marqués residía todavía en localidades rurales, mientras que solo el 32\% y 49\% de los habitantes de Colón y El Marqués, respectivamente, vivía en localidades del ámbito urbano.

Los procesos donde los habitantes rurales laboran en actividades típicamente urbanas (de los sectores secundario y terciario) solo son explicables mediante la intensificación de una movilidad sustentada en la ampliación de infraestructura carretera y la aparición de sistemas de transporte rurales y regionales que apoyan el flujo cotidiano de los habitantes de las comunidades rurales que se desplazan a las zonas industriales dispersas en la región, o a la zona metropolitana de la ciudad de Querétaro, para acceder a sus fuentes de trabajo o a servicios educativos, médicos y comerciales, entre otros.

Cabe señalar que los empleos del sector secundario para la población rural de la microrregión se ubican principalmente en el segmento de obreros de la industria manufacturera. En el sector terciario predominan las plazas de los servicios a la industria menos calificados -como son los relativos a la limpieza, la vigilancia-y las abiertas a los obreros de menor calificación. Por el contrario, los segmentos ocupacionales más calificados de la industria y del terciario industrial tienen residencia en la ciudad de Querétaro.

La transformación estructural descrita generó un cambio en las actividades productivas de la microrregión, generándose nuevos empleos para la población local, con lo que se dio un giro de las actividades agrícolas y ganaderas hacia un perfil claramente industrial. Es importante destacar que la participación de la población en la industria se da tanto por hombres como por mujeres. Esta situación ha generado que la población se mantenga en sus comunidades de origen, con lo cual el fenómeno de la emigración es poco significativo, mientras que la inmigración va en aumento. De esta manera, la población en la microrregión Navajas-Galeras se incrementa a un ritmo mayor que la de la propia ciudad. No obstante, hay matices que vale la pena resaltar. Es indudable que la cercanía del municipio de El Marqués a la ciudad de Querétaro y la mayor lejanía relativa del municipio de Colón, muestran tendencias diferenciadas en el crecimiento de la población. Efectivamente, la tasa de crecimiento medio anual de las comunidades pertenecientes a El Marqués, que se encuentran dentro de la microrregión, fue del 5,75\%, cifra muy superior a la de Querétaro, de 2,09\%, para el periodo 1995-2010. Por su parte, la tasa de crecimiento medio anual para las comunidades de la microrregión pertenecientes a Colón fue de $2,18 \%$ en el mismo periodo, dato que resulta similar a la media estatal (Consejo Estatal de Población [coespo], 2011).

Por otra parte, es importante señalar que en el rubro de los ingresos de la población económicamente activa (PEA), hay notorias diferencias entre la población rural y la semirrural de la microrregión Navajas-Galeras (donde alrededor del 60\% de la población ocupada obtiene menos de dos salarios mínimos mensuales) y la PEA ocupada de la ciudad de Querétaro, donde solo el 26\% de la población ocupada se encuentra en este rango, en tanto que un $74 \%$ alcanza ingresos superiores a los dos salarios mínimos mensuales. En el mismo sentido, mientras que la zona 
metropolitana de Querétaro presenta niveles de marginación bajos y muy bajos, en sus zonas de expansión dispersa -es decir, en las dieciocho localidades rurales de Navajas-Galeras- se presentan niveles de marginación medios y, en algunas localidades, se alcanza el rango de nivel alto (CoEspo, 2011). Es decir, en última instancia estamos hablando de los sectores de población menos favorecidos y de menores ingresos dentro de esa configuración territorial ampliada y difusa en torno a una zona metropolitana de la ciudad de Querétaro.

No obstante lo anterior, es importante mencionar que, entre 1995 y 2010, los municipios incluidos en esta expansión difusa de la zona metropolitana presentaron un crecimiento de los rangos de ingresos superiores a los dos salarios mínimos al mes. En este sentido, El Marqués y Colón duplicaron el porcentaje de su PEA con ingresos mayores a los dos salarios mínimos mensuales, al alcanzar en 2010 respectivamente el $43 \%$ y $39 \%$ de su PEA este rango de ingresos, frente al 25\% y $20 \%$ registrado en el año inicial. Así, a pesar de la pérdida relativa del poder adquisitivo del salario mínimo, fijada por algunos autores (Bolvitnik \& Damián, 2004) entre 20\% y $24 \%$ para ese periodo, la zona en cuestión muestra segmentos de la población con salarios mayores que en períodos previos. Sus gastos, sin embargo, son también mayores, por las necesidades propias del nuevo modelo de organización del territorio, donde se intensifica la movilidad y hay un encarecimiento relativo del suelo y la vivienda, entre otros servicios y bienes propios de las sociedades urbanizadas.

En consonancia con los datos de ocupación por sectores e ingresos de la PEA previamente analizado, los datos del Instituto Nacional de Estadística y Geografía (INEGI) y de COEspo seńalan la existencia de un abatimiento relativo de los niveles de marginación en las localidades de la zona de estudio. En efecto, para 2010, la información de estas instituciones muestra que once de las dieciocho comunidades de la microrregión Navajas-Galeras redujeron sus grados de marginación desde un nivel alto a un nivel medio.

\section{Expansión dispersa e intensificación de la movilidad en la microrregión Navajas-Galeras}

A la luz de la investigación de campo realizada en la microrregión Navajas-Galeras, se detectó una serie de elementos y procesos que se repiten de manera generalizada, los mismos que podrían ser considerados como característicos de esta nueva configuración territorial que hemos denominado expansión dispersa o difusa de ciudades intermedias dinámicas.

En primer lugar, los habitantes mantienen la residencia en las localidades rurales de la zona, pero han modificado rápidamente sus actividades económicas y los lugares donde las realizan. Al dedicarse mayoritariamente a labores relacionadas con los sectores secundario y terciario (industria y servicios), se ha producido un drástico alejamiento del lugar de residencia respecto al lugar donde realizan sus actividades diarias (la ciudad de Querétaro y las zonas industriales).

Derivado de lo anterior, se está produciendo una notable intensificación de la movilidad de los habitantes, que requieren viajar diariamente fuera de sus comunidades para satisfacer sus necesidades socioeconómicas. Por lo tanto, el desarrollo de sistemas de transporte regional se transforma en un elemento fundamental, en una 
condición sine qua non para soportar este nuevo patrón de organización territorial o, si se quiere, para sostener la nueva expansión difusa y dispersa que tiende a consolidarse en Querétaro y otras regiones de México.

Es en este último punto donde hay que hacer énfasis, por lo que representa en cuanto a la aparición de las nuevas tendencias territoriales. Como se señaló previamente, a diferencia de las décadas previas (entre los ańos sesenta y noventa del siglo $\mathrm{xx}$ ), donde la periferización de las ciudades consistió principalmente en la expansión constante de las franjas periurbanas hacia los márgenes de la ciudad (Kowarick, 1992), actualmente este proceso parece incluir vastas áreas de territorio donde se insertan, de manera discontinua, localidades pequeńas semirrurales y rurales dispersas en el territorio. Efectivamente, en el desarrollo de este trabajo se observa que la microrregión Navajas-Galeras se ha sumado claramente a esta tendencia de organización del espacio regional de Querétaro.

En este contexto, los habitantes de poblados rurales como los señalados están fuertemente involucrados con las actividades urbanas y requieren desplazarse a la ciudad mayor o a ciertas islas de actividades económicas secundarias y/o terciarias (es decir, típicamente urbanas), localizadas de manera dispersa en ámbitos rurales, como los parques industriales en torno a la microrregión de estudio. Sin duda, el elemento que cohesiona esta dispersión relativa es el desarrollo de una infraestructura y un sistema de transporte regional que articule esa creciente fragmentación territorial. Así, en el actual proceso de dispersión de las actividades urbanas, los sistemas de transporte incluyen no solo la expansión de las redes de transporte urbano de pasajeros, sino la conformación de verdaderos sistemas regionales de transporte, con redes y nodos o terminales propios, distintos a los del transporte urbano. En el ámbito en estudio, estos sistemas regionales vinculan, por un lado, a las comunidades rurales de la microrregión Navajas-Galera; y, por otro, a la ciudad de Querétaro, articulando territorialmente la dispersión espacial de este modelo en boga de ciudad difusa.

Metodológicamente, para medir y comprender cómo se lleva a cabo la movilidad de pasajeros en la microrregión Navajas-Galeras, se optó por aplicar una encuesta origen-destino directamente a los usuarios de transporte público que viven en cada una de las dieciocho comunidades que conforman el área de estudio. En este sentido, para determinar el número de encuestas origen-destino que se realizarían, se obtuvo el dato de la población total mayor de quince años (según el Censo de Población y Vivienda de 2010), aplicando la fórmula para una proporción poblacional de acuerdo con los planteamientos de representatividad de la muestra de William Mendenhall (2006) ${ }^{1}$.

En la figura 2 se representan las líneas de deseo de los viajes de las personas, correspondientes a los resultados de la encuesta de origen-destino aplicada en la microrregión de estudio, donde se demuestra fehacientemente cómo los movimientos de la población se vinculan principalmente con la ciudad de Querétaro y su zona metropolitana.

1 Se usó la fórmula recomendada por Mendenhall (2006) de asignar a “p” =0,5, para obtener tamaños de muestra conservadores. El resultado es un tamaño de muestra de 390 encuestas origen-destino por aplicar en el área de estudio, con 95\% de nivel de confianza y un error de estimación (B) de 5\%. 
FIGURA 2 Principales líneas de deseo en la región Navajas-Galeras

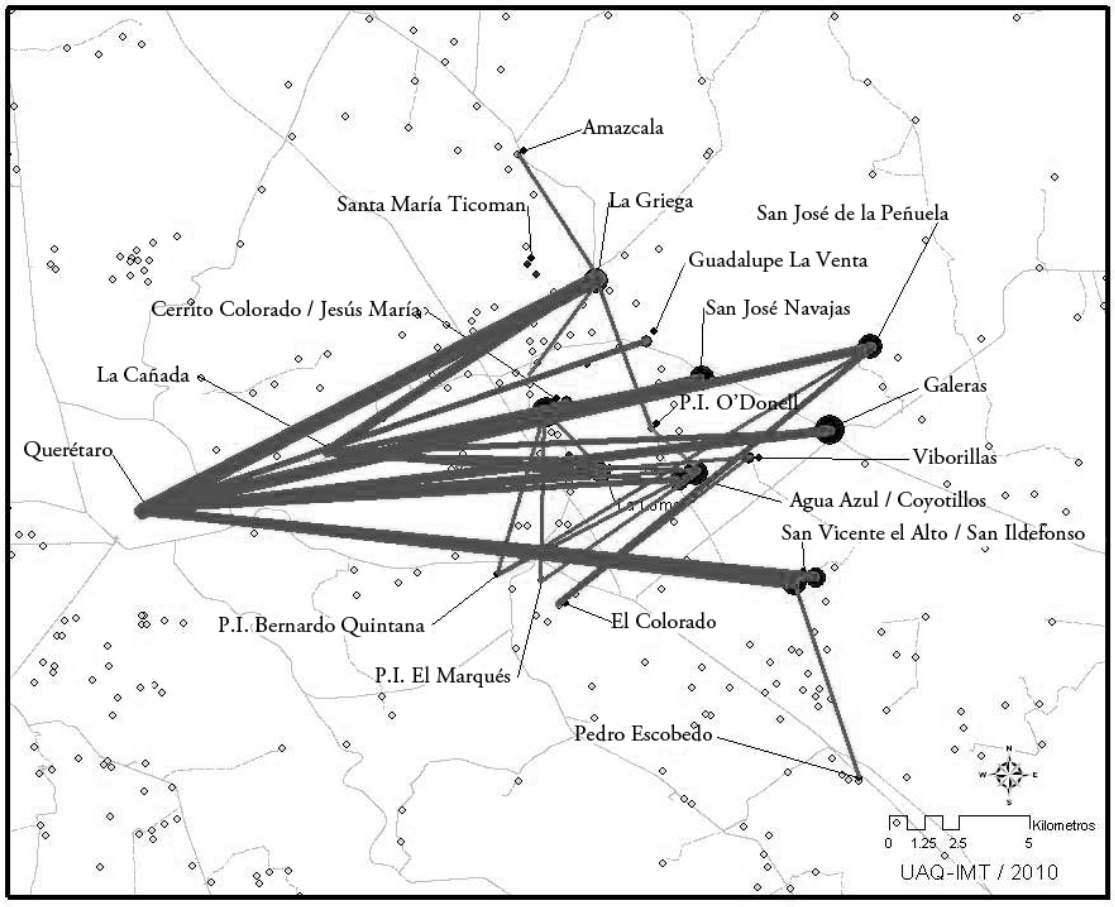

FUENTE ELABORACIÓN PROPIA CON BASE EN LA MATRIZ ORIGEN-DESTINO DE VIAJES DIARIOS EQUIVALENTES, 2010

Así, los sistemas territoriales complejos y difusos no se dan, como pudiera pensarse, solo en torno a las grandes metrópolis. Lo propio sucede alrededor de centros urbanos intermedios dinámicos. En este sentido, el reajuste territorial propiciado por la apertura económica neoliberal en el caso de las ciudades intermedias no se expresa solo en el crecimiento de sus áreas urbanas, sino en relación con su entorno regional. La mayor importancia que adquieren estos centros urbanos intermedios, la mayor cantidad y diversidad de servicios que ofrecen, la cantidad de actividades productivas que desarrollan, genera vínculos más intensos con las zonas rurales contiguas. En la medida en que el ámbito rural aparece cada vez más articulado al ámbito urbano; en que hay una creciente interrelación entre campo y ciudad; en que los habitantes del medio rural, por su escaso dinamismo económico, se hacen más dependientes y subordinados a la economía urbana, tiende a producirse una mayor movilidad regional ${ }^{2}$, más que procesos de migración definitiva. Este último

2 En México, diversos estudios revelan el aumento de la movilidad regional en los últimos años; entre ellos, del Consejo Nacional de Población (CONAPo), Sistema de ciudades y distribución espacial de la población en México (1991) y Estudio socioeconómico y demográfico del subsistema de ciudades de Querétaro (1995); de la Secretaría de Desarrollo Social, Consejo Nacional de Población e Instituto Nacional de Estadística y Geografía, Delimitación de las zonas metropolitanas de México 2010 (2012); y de C. Martner, A. Balbuena, A. Bustos y E. de La Torre, Transporte y territorio. Movilidad regional en San Juan del Río (2008), entre otros. 
es un fenómeno reciente en México y América Latina que ha sido poco estudiado, a pesar de que tiene un fuerte impacto en la transformación territorial reciente y en la conceptualización de las tendencias de concentración y dispersión (Martner, 1996).

Lo cierto es que los patrones y motivos de la movilidad, además de haberse intensificado, han cambiado de contenido. La información aportada por el estudio de origen-destino en la zona de estudio muestra que los motivos principales de los viajes son por trabajo, por educación y por servicios de salud y administrativos (gráfico 1).

\section{GRÁfICo I | Principales motivos de viaje en la microrregión Navajas-Galeras}

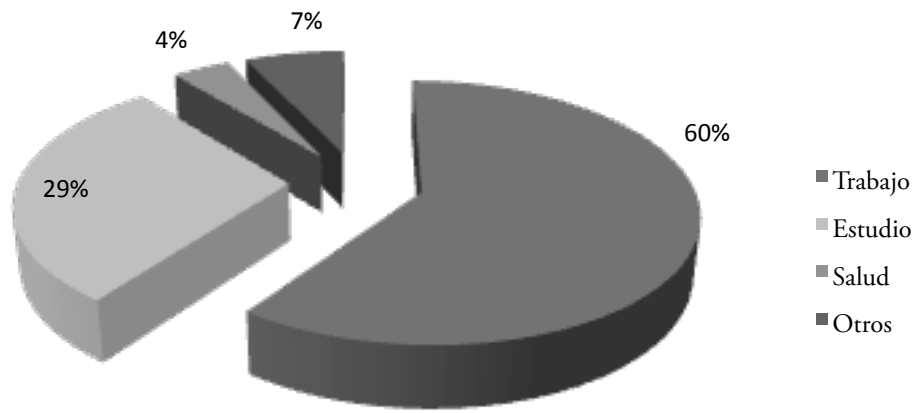

FUENTE ELABORACIÓN PROPIA A PARTIR DE LA BASE DE DATOS DE LA ENCUESTA ORIGEN-DESTINO, 2OIO

Pero el fenómeno es todavía más impactante, puesto que los poblados rurales de la microrregión muestran un patrón de movilidad que podría ser considerado típicamente urbano, es decir, donde predomina una intensidad diaria de los viajes en los días hábiles, a diferencia del periodo previo a los ańos noventa, en el cual, de acuerdo con los estudios de Espino (1995) y del Consejo Nacional de Población (COESPo) (1995), la movilidad regional solía caracterizarse por una menor intensidad y una periodicidad más espaciada, con viajes semanales, quincenales o mensuales, donde habitantes de poblados menores o zonas rurales satisfacían servicios específicos de tipo social, comercial o administrativo, pero no sus actividades diarias. Por el contrario, ahora los resultados de la encuesta origen-destino 2010 muestran una alta periodicidad de viajes por pasajero. Entre las características de la movilidad regional, la frecuencia de traslados con mayor ocurrencia fue la correspondiente a cinco viajes de ida y vuelta por pasajeros/semana (lunes a viernes), con cerca del 50\%, seguida por la de seis viajes redondos por pasajero/semana, con $23 \%$.

El gráfico 2 permite concluir que el $80 \%$ de los viajes tiene una frecuencia de cinco viajes redondos o más por pasajero/semana.

Actualmente se observa que este patrón tan típicamente urbano de desplazamientos diarios se ha desdoblado hacia el ámbito rural vinculado a la ciudad, es decir, se ha proyectado sobre una vasta región. En este sentido, lo que tradicionalmente se ha considerado como ámbito rural aparece cada vez más articulado o integrado a las dinámicas urbanas. Crecientemente sus habitantes realizan actividades 
en la urbe o asociadas a ella. En esa medida, el campo también se urbaniza, aunque en forma desigual y fragmentada. Así, una peculiaridad de las tendencias de concentración y dispersión actuales, en muchas regiones de México, es que la opción de migración del campo hacia una ciudad mayor ha perdido fuerza; es decir, se da a menor ritmo con respecto al periodo anterior, frente a la opción de mantener el lugar de residencia en localidades campesinas cercanas, a costa de intensificar el ritmo de desplazamiento entre el ámbito de difusión metropolitano (con sus localidades rurales y semirrurales) y la ciudad central o compacta.

\section{GRÁfICO 2 Frecuencia de los viajes por pasajero en la microrregión Navajas-Galeras}

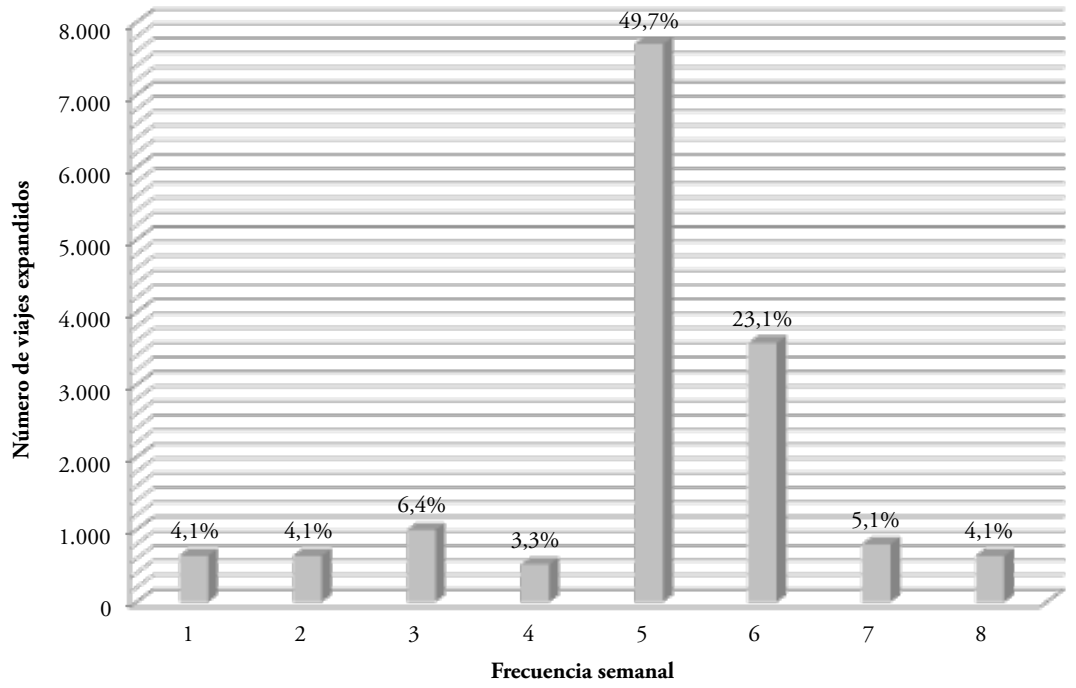

FUENTE ELABORACIÓN PROPIA A PARTIR DE LA BASE DE DATOS DE LA ENCUESTA ORIGEN-DESTINO, 20 IO

$\mathrm{Al}$ respecto, Espino (1995) considera esta movilidad pendular del campo a la ciudad como una nueva forma de migración, ya no definitiva como en periodos previos, sino de tipo temporal o intermitente, que también denomina "migración fugaz", donde el retorno constante al medio rural evita una mayor concentración urbana y "aligera el gasto social que el Estado debería proveer a esos trabajadores a cambio de los impuestos y la riqueza que generan en la ciudad" (p. 54). En efecto, los elevados precios de la vivienda y los servicios en la ciudad y el control más efectivo sobre las invasiones de terrenos urbanos (tan comunes en las décadas de los sesenta y setenta), han dificultado el cambio de residencia de los pobladores de bajos ingresos de las zonas rurales (González \& Martner, 2011). Sin embargo, sus vinculaciones con el ámbito urbano, lejos de disminuir, se han incrementado y, en este sentido, tiende a consolidarse en muchas metrópolis y ciudades intermedias dinámicas una forma de organización territorial extensa y difusa, apoyada fuertemente en el desarrollo de corredores de transporte regional, que actúan en un radio cada vez más amplio a partir de las ciudades principales (Martner et al., 2008). 
Según datos empíricos, el radio de extensión de densos corredores de transporte en torno a ciudades intermedias rebasa los 50 kilómetros, los cuales abarcan gran cantidad de poblados rurales dispersos. La manera de integrar esos fragmentos dispersos del territorio a la urbe principal es a través de la conformación de corredores regionales de transporte y también mediante la formación de sistema de transporte rural (Martner, Balbuena, Bustos \& De La Torre, 2008).

En el contexto de las tendencias recientes señaladas, hay al menos cinco elementos peculiares importantes de destacar en la microrregión Navajas-Galeras, los mismos que se desprenden del trabajo de campo y de las entrevistas realizadas a los actores clave:

- La intensificación de la movilidad en la zona se manifiesta en la consolidación de los servicios de transporte público regional, que ofrecen una creciente frecuencia de viajes desde y hacia la ciudad de Querétaro. Actualmente hay servicios disponibles cada treinta minutos, y en ellos se movilizan principalmente trabajadores de la construcción, empleadas de servicio doméstico y del comercio, así como estudiantes de nivel bachillerato.

- Una particularidad muy significativa de esta microrregión es que en los espacios y actividades donde el servicio de transporte público no satisface adecuadamente las exigencias de movilidad de la población trabajadora, se han establecido servicios privados o contratados de transporte con itinerarios y horarios específicos para el traslado de las personas. Esto constituye típicamente la solución implementada por los parques industriales, que se encuentran dispersos como "islas de urbanización" dentro del entorno rural propio de la región de estudio. En este caso, la necesidad de traslado justo a tiempo para los cambios de turno en las plantas industriales ha llevado a las empresas a implementar servicios de transportación particular, que hacen recorridos predeterminados por distintas localidades rurales de la región, para recoger a los trabajadores y trabajadoras del turno entrante y llevar de vuelta a sus comunidades a los que concluyeron su jornada laboral. Es precisamente la posibilidad de conseguir fuerza de trabajo barata en el ámbito rural lo que permite a las empresas financiar un transporte expedito y seguro en cuanto a los tiempos de recorrido y puntualidad en los cambios de turno, para evitar la detención de las líneas de producción y mantener la continuidad en sus procesos.

- Resulta relevante destacar el hecho de que la mayor parte del personal de las industrias que se mueve en el transporte contratado por las empresas es población femenina de un rango de edad muy joven (18-25 años), a diferencia del transporte público regional, en el que los trabajadores que se desplazan a la ciudad tienden a ser de mayor edad y hay más participación de población masculina. A decir de los informantes, este hecho se debe a que la industria se nutre sobre todo de trabajadoras jóvenes con perfiles de mayor compromiso y responsabilidad en el trabajo que sus pares masculinos, y con comportamientos menos conflictivos o reivindicativos en términos laborales. Los diversos informantes calificados coincidieron en señalar que la industria asentada en la región suele no contratar a obreros u obreras mayores de 35 ańos. 
- Si bien es cierto que el precio del suelo se ha incrementado en la microrregión Navajas-Galeras, sobre todo a partir de la construcción del Aeropuerto Internacional de Querétaro, los costos de los terrenos y las viviendas en las comunidades rurales de la zona son todavía notablemente menores que los de la ciudad. Este cuadro inhibe procesos de migración permanente a la ciudad por parte de los sectores de menor ingreso (González \& Martner, 2011) y acentúa el modelo de organización territorial basado en la intensificación de la movilidad que es soportado por el sistema de transporte regional. Lógicamente, una exploración más exhaustiva de este tópico en particular constituye una veta importante para estudios posteriores.

- Tal como se demostró en el análisis previo, realizado en el inciso sobre la transformación regional acelerada, el nivel de ingresos de la población de la microrregión ha crecido en términos de los salarios mínimos oficiales. No obstante, los gastos de las familias también se han incrementado al tener que asumir los costos adicionales que implica esta nueva ruralidad crecientemente urbanizada; o, mejor dicho, los costos que implica pertenecer a esta ciudad difusa, donde se intensifica el uso de una serie de servicios que antes tenían menor peso en la economía de los habitantes del campo. Los egresos relacionados con la intensificación de la movilidad son nuevamente un ejemplo de esta situación. También los procesos de encarecimiento progresivo del suelo suponen la necesidad de contar con mayores ingresos para permanecer en la zona. En este sentido, es previsible que los sectores de menores ingresos de la microrregión tiendan a mover su domicilio hacia las comunidades más alejadas y con menores servicios de la región, donde no hay tanta presión sobre los precios del suelo, por no ser aún espacios rentables en términos del capital inmobiliario. Por el contrario, los desarrollos de vivienda formal en conjuntos habitacionales de ingresos bajos y medios anuncian tanto un crecimiento poblacional como un recambio relativo de los habitantes, al incorporarse a la zona población que emigró de otras ciudades y estados de la república.

\section{Los dilemas actuales de la planeación urbano-regional: de la planeación indicativa a la ordenación del territorio por el mercado}

Bajo el modelo capitalista, la ordenación del territorio es proclive a mostrar crecimientos más o menos desordenados y anárquicos en las ciudades y regiones, debido al carácter privado tanto de la propiedad de los medios de producción como de la apropiación de la producción social; y, con ello, al carácter individual de las decisiones de apropiación del territorio y de la producción de objetos inmobiliarios, como atinadamente ha expresado Pradilla (1984). En esta línea, el actual periodo presenta diferencias notables con el periodo previo en cuanto a los alcances de la planeación y la toma de decisiones sobre el desarrollo territorial. Hoy, el Estado se ha retraído de muchos ámbitos de acción donde antes tenía un mayor peso, como es el caso del control y modificación de los usos del suelo y de la inducción de actividades productivas, habitacionales, de esparcimiento, etcétera. 
Así, aunque en el periodo de sustitución de importaciones comenzaron a notarse signos claros de crecimiento urbano disperso y anárquico, con deseconomías de aglomeración, todavía se evidenciaba la injerencia estatal. Sujeto todavía a los esquemas de planeación indicativa, el Estado generaba emprendimientos directos sobre el territorio, como el desarrollo de parques industriales construidos por el sector público o zonas habitacionales promovidas en márgenes urbanos, donde la presión de las rentas del suelo eran menores, entre otros. Por ejemplo, algunas de las acciones más notables en materia de desconcentración impulsadas por el Estado fueron la localización de empresas paraestatales en ciudades menores y el establecimiento de estímulos para el desarrollo de parques industriales en ciudades intermedias y pequeñas del país, mediante la política de polos de desarrollo implementada durante los ańos sesenta y setenta, cuando se hicieron más evidentes algunas deseconomías de aglomeración.

Paradójicamente, algunas de las ciudades menores que recibieron los beneficios de las políticas territoriales estatales desconcentradoras han alcanzado en la actual fase de apertura comercial dinámicos procesos económico-demográficos y se han insertado con mayor facilidad que algunas ciudades mayores en las cadenas productivas globalizadas que dominan el panorama actual. Se han producido con ello nuevas tendencias de estructuración territorial, como ha quedado evidenciado para el caso de la zona metropolitana de la ciudad de Querétaro y su ámbito de expansión.

No obstante, con el agotamiento del modelo de sustitución de importaciones y el advenimiento del llamado modelo neoliberal, que privilegia la apertura comercial y económica, la privatización de empresas, servicios y actividades que previamente realizaba el Estado, los márgenes de la propia planeación indicativa se han ido progresivamente reduciendo a su mínima expresión. Lógicamente, la microrregión Navajas-Galeras no escapa a esta tendencia, donde la planeación territorial ha cedido espacio a la ordenación del territorio por el mercado. En efecto, aunque existe una instancia encargada de la planeación urbana y regional en Querétaro, que incluso ha elaborado un plan parcial de desarrollo de la microrregión en cuestión, en el cual se establecen los cambios de usos del suelo, las zonas de desarrollo habitacional, industrial y de servicios, así como las tendencias sociodemográficas esperables en el mediano y largo plazo, lo cierto es que, en paralelo, existen otras dos instancias de diferentes niveles de gobierno que toman decisiones sobre la autorización de actividades y los cambios de uso del suelo. De esta forma, la instancia encargada de las actividades económicas y de la atracción de inversiones en el Estado de Querétaro revisa y, en su caso, autoriza los proyectos de desarrollos industriales, comerciales y de servicios que le presentan inversionistas privados y desarrolladores inmobiliarios, con criterios propios que no necesariamente son los del organismo de planeación urbana y regional o los del plan parcial de Navajas-Galeras.

Más independiente aún es la actuación de los municipios involucrados en la zona de estudio, que tienen plena jurisdicción para cambiar los usos del suelo a través de sus respectivos cabildos, cuando hay solicitudes concretas de agentes económicos privados. Es evidente que las necesidades y prioridades de los gobiernos municipales son distintas a las de las otras instancias estatales, sobre todo tratándose de 
municipios con escasos recursos, donde la posibilidad de realizar cambios de suelo rural a suelo de tipo industrial, comercial, habitacional o de servicios va a significar un incremento sustancial de los ingresos del Ayuntamiento vía impuestos (predial, aprovechamientos, etcétera).

Ante este marco de lógicas diferenciadas, donde el mercado - es decir, los actores privados- tiene acceso de diversas formas a la utilización del territorio y a los cambios de usos del suelo según sea la actividad que se quiera realizar, incluso la que es meramente especulativa, probablemente tiendan a agudizarse la fragmentación, dispersión y/o expansión difusa en el desarrollo territorial. Tal como señalan De Mattos y Fuentes (2012), "otro de los factores fundamentales de estos cambios en la forma urbana tiene que ver con los nuevos arreglos institucionales impulsados por la nueva gobernanza neoliberal, donde el mercado juega un rol central y el espacio urbano se encuentra altamente mercantilizado" (p. 1). De esta manera, en un escenario inercial puede anticiparse un crecimiento desordenado de la microrregión Navajas-Galeras, donde los usos habitacionales, industriales y comerciales surgen en principio como islotes urbanizados que se van insertando en el territorio, sin que exista una lógica de mejor aprovechamiento sostenible del espacio y una combinación racional de usos del suelo que beneficie a la población local. De hecho, la actual tendencia de modificación de los uso del suelo y ocupación del territorio, sin duda sumamente especulativa, ni siquiera resulta siempre funcional desde la perspectiva de la racionalidad económica y la competitividad de las cadenas productivas.

Respecto de lo anterior, resulta emblemático el caso reciente del proyecto de desarrollo de una terminal multimodal y centro de actividades logísticas para atender a las empresas de la zona en terrenos de la microrregión Navajas-Galeras, donde convergen las vías de las dos principales empresas ferroviarias del país. Dicho desarrollo ha quedado limitado por el alto costo del suelo en esa zona, y no existen reservas de tierras estatales o municipales que pudiesen coadyuvar a encontrar alternativas competitivas en términos de los análisis de costo-beneficio. Esta situación, a decir de los actores privados interesados en desarrollarlo, ha hecho que dicho proyecto sea económicamente poco viable. Así, la ordenación del territorio dejada exclusivamente a cargo de la mano invisible del mercado, puede terminar resultando disfuncional a los propios intereses de la reproducción ampliada del capital.

Por otra parte, en el caso de los sectores de menores ingresos de Navajas-Galeras, la continuidad del escenario actual probablemente conduzca, como se mencionó previamente, a una migración relativa hacia comunidades más alejadas de la región y con menos servicios, donde no hay tanta presión sobre los precios del suelo, por no ser aún espacios rentables en términos del capital inmobiliario. Por el contrario, los desarrollos de vivienda formal en conjuntos habitacionales de ingresos bajos y medios anuncian tanto un crecimiento poblacional como un recambio relativo de los habitantes, al incorporarse a la zona la población que emigró de otras ciudades y estados de la república.

Lo cierto es que los escenarios tendenciales no auguran una sostenibilidad de largo plazo de la microrregión en ninguna de las tres vertientes del proyecto; es decir, ni en la socioterritorial, ni en la económica, ni en la ambiental se alcanzará un patrón sustentable, si no se modifica la perspectiva actual de la planeación 
urbano-regional en la zona, que en los hechos no opera como tal, sino como una suerte de ordenación territorial conducida por las llamadas fuerzas del mercado.

Por lo tanto, cabe hacer una recomendación a los organismos de Gobierno, usuarios potenciales de esta investigación, en cuanto a valorar la posibilidad y necesidad de revisar el actual esquema de planeación y toma de decisiones sobre la ordenación del territorio. Es evidente la importancia no solo de una interacción y coordinación mayor entre las distintas esferas y niveles de gobiernos relacionados con el tema, sino también de una planeación prospectiva con una visión estratégica, donde el Estado cuente con herramientas de regulación que le permitan avanzar hacia un desarrollo medianamente sostenible en las tres vertientes principales analizadas en el curso de este proyecto: la socioterritorial, la económica y la ambiental.

\section{Reflexiones finales}

A la luz del análisis previo, se observa que las transformaciones socioterritoriales de la llamada microrregión Navajas-Galeras forman parte de un proceso de expansión disperso, difuso -y, por ello, en buena medida anárquico o desordenado- de la Zona Metropolitana de la Ciudad de Querétaro.

En este sentido, el fenómeno urbano no puede ser cabalmente entendido sin incorporar en el análisis su articulación con el ámbito regional. Conceptualmente, esto implica que, en el nuevo marco de reorganización territorial, tiende a desdibujarse cada vez más la división tajante establecida tradicionalmente entre campo y ciudad. Lo que en última instancia están mostrando estas tendencias es la necesidad de revisar críticamente algunos esquemas conceptuales aceptados de manera generalizada en el análisis territorial, como la dicotomía rural-urbana o urbano-regional. En la actualidad, lo urbano y lo rural no pueden ser cabalmente entendidos sin conocer su funcionamiento regional. Por ello, el enfoque sistémico de organización espacial presenta mayor consistencia para la comprensión de los nuevos fenómenos de vinculación entre áreas rurales y urbanas.

Ahora bien, cabe señalar que la aportación de este trabajo no solo se circunscribe a verificar la tendencia hacia la expansión dispersa de una metrópoli intermedia en México. Busca adicionalmente revelar los elementos clave que sustentan tal modelo territorial, en el que es necesario tomar en cuenta el análisis de determinadas condiciones generales para la producción que desempeñan un papel crucial en la concentración y la dispersión territorial. Es el caso de los sistemas de transportes y las comunicaciones; y ello especialmente en este periodo, en el cual la reconstitución del sistema capitalista a nivel mundial pasa por una fuerte fragmentación de los procesos económicos y sociales.

Así, una segunda conclusión considera que el sistema de transporte regional se está convirtiendo en un elemento estratégico de articulación espacial para la nueva configuración territorial en la que se inserta la microrregión Navajas-Galeras.

Una característica significativa en las tendencias socioterritoriales detectadas en la microrregión Navajas-Galeras es que los habitantes de la zona mantienen la residencia en las localidades rurales, pero han modificado rápidamente sus actividades económicas y los lugares donde las realizan. Al dedicarse mayoritariamente a labores 
relacionadas con los sectores secundario y terciario (industria y servicios), se ha producido un drástico alejamiento del lugar de residencia respecto al lugar donde realizan sus actividades diarias (la ciudad de Querétaro y las zonas industriales).

Derivado de lo anterior, se está produciendo una notable intensificación de la movilidad de los habitantes, que requieren viajar diariamente fuera de sus comunidades para satisfacer sus necesidades socioeconómicas. Por lo tanto, el desarrollo de sistemas de transporte regional se transforma en un elemento clave, en una condición sine qua non para soportar este nuevo patrón de organización territorial o, si se quiere, para sostener la nueva ruralidad que tiende a consolidarse en Querétaro y otras regiones de México.

En este contexto, los habitantes de estos poblados rurales están mucho más involucrados con las actividades urbanas y requieren desplazarse a la ciudad mayor o a ciertas islas de actividades económicas secundarias y/o terciarias (es decir, típicamente urbanas), localizadas de manera dispersa en ámbitos rurales, como los parques industriales en torno a la microrregión de estudio. Sin duda el elemento que cohesiona esta dispersión relativa es el desarrollo de una infraestructura y un sistema de transporte regional que articule esa creciente fragmentación territorial. Así, en el actual proceso de expansión dispersa de la ciudad o, si se quiere, de regionalización difusa de las actividades urbanas, la alteración de los sistemas de transporte incluye no solo la expansión de las redes de transporte urbano de pasajeros, sino la conformación de sistemas regionales de transporte para la movilización de crecientes contingentes de población, generalmente de bajos ingresos, que tienen su residencia no en la periferia urbana, sino en localidades rurales, y que se dirigen cotidianamente a una ciudad mayor o a los parques industriales diseminados sobre la región.

En tercer lugar, y a la luz del análisis previo, puede concluirse que, aunque los indicadores sobre marginación muestran un avance importante en la zona de expansión difusa, aún hay importantes carencias en la cobertura de los servicios básicos, y los niveles de ingreso promedio son todavía notablemente inferiores a los de la zona metropolitana de la ciudad de Querétaro. Por eso se puede afirmar que los sectores más pobres de esta configuración territorial ampliada y dispersa en torno a la zona metropolitana de Querétaro se localizan más allá de la periferia de la ciudad, en esos fragmentos espaciales que forman los poblados rurales o semirrurales exteriores al continuo urbano. En otros términos, puede señalarse que los trabajadores urbanos de menores ingresos tienen su residencia fuera de la ciudad; esto es, en el ámbito rural o, mejor aún, en los fragmentos dispersos de la región circundante de esta dinámica ciudad intermedia mexicana.

En este orden de cosas, resulta incomprensible que cuando se estudian las tendencias urbanas generadas por las políticas liberales, se ignoren o excluyan del análisis los crecientes sectores sociales ubicados fuera de los márgenes de la ciudad, pero vinculados estrechamente a la urbe y a su funcionamiento.

En definitiva, se atisban nuevas formas de concentración difusa y nuevas desigualdades sobre una configuración territorial ciertamente novedosa, sostenida fuertemente en la intensificación de la movilidad de la población mediante el desarrollo de extensos sistemas regionales de transporte sobre los cuales habrá que seguir profundizando en estudios posteriores. 


\section{Referencias bibliográficas}

Aguilar, A., Graizbord, B. \& Sánchez, A. (1996). Las ciudades intermedias y el desarrollo regional en México. México, Consejo Nacional para la Cultura y las Artes, Dirección General de Publicaciones (conaculta)/Universidad Nacional Autónoma de México (unam)/ El Colegio de México.

Álvarez, G. (2011). Estructura y temporalidad urbana de las ciudades intermedias en México. Frontera Norte, 23(46), 91-124. En http://www.redalyc.org/articulo. oa?id=13619212004

Anzaldo Gómez, C. \& Rivera Vázquez, A. (2006). Evolución demográfica y potencial de las ciudades de México. En Consejo Nacional de Población (Conapo), La situación demográfica en México 2006 (pp. 207-231). México, D.F.: CONAPO. En http://www. conapo.gob.mx/es/CONAPo/La_situacion_demografica_de_Mexico_2006

Boltvinik, J. \& Damián, A. (2004). La pobreza en México y el mundo. Realidades y desafios. México, D.F.: Siglo XxI.

Borsdorf, A. (2003). Cómo modelar el desarrollo y la dinámica de la ciudad latinoamericana. EURE, 29(86), 37-49. http://dx.doi.org/10.4067/S0250-71612003008600002

Cal y Mayor, R. (1994). Ingeniería de Tránsito. México, D.F.: Alfaomega.

Cariola, C. \& Lacabana, M. (2001). La metrópoli fragmentada: Caracas entre la pobreza y la globalización. EURE,, 27(80), 9-32. http://dx.doi.org/10.4067/S025071612001008000002

Castells, M. (1997). La era de la información. Economia, sociedad y cultura. La Sociedad Red. Vol. 1. Madrid: Alianza.

Consejo Estatal de Población (COEsPo). (1995). Estudio socioeconómico y demográfico del subsistema de ciudades de Querétaro. Querétaro: CONAPO-COESPO,.

Consejo Estatal de Población (COESPO). (2011). Información socioeconómica y demográfica del estado de Querétaro. Querétaro: Autor.

Consejo Nacional de Población (CONAPo). (1991). Sistema de ciudades y distribución espacial de la población en México (2 vols.). México, D.F.: Autor.

Consejo Nacional de Población (CONAPo). (1995). Estudio socioeconómico y demográfico del subsistema de ciudades de Querétaro. México, D.F.: Autor.

Coraggio, J. L. (1987). Los complejos territoriales dentro del contexto de los subsistemas de producción y circulación. Quito: Textos de Ciudad.

Delgado, J. (1998). Ciudad-Región y transporte en el México Central. México, D.F.: Plaza \& Valdez.

De Mattos, C. (1983). Las ciudades intermedias en las estrategias de reorganización espacial: Propósitos, modalidades, viabilidad. México, D.F.: Instituto Latinoamericano y del Caribe de Planificación Económica y Social (ILPes)-El Colegio de México (colmex).

De Mattos, C. (2006). Modernización capitalista y transformación metropolitana en América Latina: cinco tendencias constitutivas. En A. I. G. Lemos, M. Arroyo \& M. L. Silveira (Eds.) América Latina: cidade, campo e turismo (pp. 41-73). São Paulo: Consejo Latinoamericano de Ciencias Sociales (ClACso)-Universidade de São Paulo.

De Mattos, C. (2010). Gobalización y metamorfosis urbana en América Latina. Colección Textos Urbanos N. ${ }^{\circ}$ 4. Quito: Organización Latinoamericana y del Caribe de Centros Históricos (Olacchi)-Municipio Metropolitano de Quito. 
De Mattos, C. \& Fuentes, L. (2012). Crecimiento de la población de Santiago entre 2002 y 2012: ‘compactación o expansión? Una falsa disyuntiva. Planeo, 8 (noviembrediciembre). En http://revistaplaneo.uc.cl/planeo-academia/articulos-centrales/ crecimiento-de-la-poblacion-de-santiago-entre-2002-y-2012-compactacion-oexpansion-una-falsa-disyuntiva/

Espino, G. (1995). La población flotante de la ciudad de Querétaro. Revista Sociología (Querétaro) (10), 48-59.

Fernández, A. (2003). Las pautas del crecimiento urbano posindustrial: de la rururbanización a la ciudad difusa. Ería, (60), 88-92. En dialnet.unirioja.es/descarga/articulo/653509.pdf

Formigo, J. \& Aldrey, J. A. (2005). Periurbanización y rururbanización en Galicia. Edición Biblioteca Virtual Miguel de Cervantes. En http://www.cervantesvirtual.com/obra/ periurbanizacin-y-rururbanizacin-en-galicia-0/

González, O. (2012). Sistemas productivos locales en América Latina: revisión de alcances y límites. Espiral (Guadalajara), 19(53), 9-31. En http://www.redalyc.org/articulo. oa?id $=13823075001$

González, O. \& Martner, C. (2011). Efectos socioterritoriales del Aeropuerto Internacional de Querétaro y del Complejo Aeroespacial en la Microrregión Metropolitana de Querétaro y municipios colindantes al AIQ. Segundo Informe Técnico. Proyecto FOMIX. Querétaro: Gobierno del Estado de Querétaro-Consejo Nacional de Ciencia y Tecnología (CONACYT).

González, O. \& Nieto, R. (2007). Comportamiento logístico de las empresas de manufactura en Querétaro, México. Economía, Sociedad y Territorio, 6(24), 953-974. En http:// www.redalyc.org/articulo.oa?id=11162404

Graizbord, B. (1992). Sistema urbano, demografía y planeación, Revista Ciudades (México, Red Nacional de Investigación Urbana), 13(12), 40-47.

Hidalgo, R. (2004). De los pequeños condominios a la ciudad vallada: las urbanizaciones cerradas y la nueva geografía social en Santiago de Chile (1990-2000). EURE, 30(91), 29-52. http://dx.doi.org/10.4067/S0250-71612004009100003

Hiernaux, D. (1993) Región, regionalismo y modernización en América Latina. Revista Ciudades, (18), 3-11.

Janoschka, M. (2006). El modelo de ciudad latinoamericana. Privatización y fragmentación del espaciourbano de Buenos Aires: el caso Nordelta. En M. Welch (Ed.), Buenos Aires a la deriva. Transformaciones urbanas recientes (pp. 96-131). Buenos Aires: Biblos.

Jirón, P. \& Mansilla, P. (2014). Las consecuencias del urbanismo fragmentador en la vida cotidiana de habitantes de la ciudad de Santiago de Chile. EURE, 40(121), 5-28. http://dx.doi.org/10.4067/S0250-71612014000300001

Kowarick, L. (1992). La crisis urbana y la ciudadanía en São Paulo. Trad. L. Echevrría. En F. Carrión (Coord.), Ciudades y políticas urbanas en América Latina (pp. 187-195). Quito: CODEL. En http://works.bepress.com/cgi/viewcontent.cgi?article=1262\&cont ext=fernando_carrion

Link, F. (2008). De la policentralidad a la fragmentación en Santiago de Chile. Revista de la Organización Latinoamericana y del Caribe de Centros Históricos, (2), 13-24. En http:// www.redalyc.org/articulo.oa?id=115112535002 
Leborgne, D. \& Lipietz, A. (1990). Nuevas tecnologías, nuevas formas de regulación: algunas consecuencias espaciales. En F. Alburquerque, C. De Mattos \& E. Jordán (Eds.), Revolución tecnológica y reestructuración productiva: impactos y desafios territoriales (pp. 103-135). Buenos Aires: Instituto Latinoamericano y del Caribe de Planificación Económica y Social (ILPEs/OnU)-Instituto de Estudios Urbanos (IEU), P. Universidad Católica de Chile-Grupo Editor Latinoamericano.

Lefebvre, H. (1976). De lo rural a lo urbano. Buenos Aires: Lotus Mare.

Martner, C. (1996). Transporte y concentración territorial en América Latina: tendencias recientes. Ciudad y Territorio, 28(110), 651-661.

Martner, C., Balbuena, A., Bustos, A. \& De La Torre, E. (2008). Transporte y territorio. Movilidad regional en San Juan del Río. Querétaro: Instituto Mexicano del Transporte (IмT)-Consejo Nacional de Ciencia y Tecnología (CONACYT).

Mendenhall, W. (2006). Elementos de muestreo. México, D.F.: Paraninfo.

Méndez, R. (1994). Reestructuración industrial y nuevos desequilibrios territoriales. Revista Ciudades, 6(21), 3-13.

Palacios, J. J. (1983). El concepto de región: La dimensión espacial de los procesos sociales. Revista Interamericana de Planificación, 17(66), 56-68. En http://www.ucla.edu. ve/dac/Departamentos/AdmPubII/materiales/EL\%20CONCEPTO\%20DE\%20 REGION.pdf

Parnreiter, Ch. (2003). Polarización económica y fragmentación espacial: El caso de México. Actas latinoamericanas de Varsovia, N. ${ }^{\circ}$ 26, 171-190.

Pradilla, E. (1984). Contribución a la crítica de la teoría urbana. Del espacio a la crisis urbana. México, D.F.: Editorial Universidad Autónoma Metropolitana.

Racionero, L. (1978). Sistemas de ciudades y ordenación del territorio. Madrid: Alianza Universidad.

Ramírez, B. \& Pradilla, E. (1993). El tratado norteamericano de libre comercio y la integración territorial de México a Estados Unidos. Revista Interamericana de Planificación, 26(103), 19-54. En http://bit.ly/1 kmAzY5

Rofman, A. (1984). Subsistemas espaciales y circuitos de acumulación regional. Revista Interamericana de Planificación, 18(70), 3-21.

Sánchez, A. \& Propin E. (2001). Cambios en la orientación funcional de las ciudades medias del trópico mexicano. Cuadernos Geográficos (31), 69-85. En http://www.redalyc.org/ articulo.oa?id=17103104

Sassen, S. (1991). The Global City: New York, London, Tokyo. Nueva York: Princeton University Press.

Sassen, S. (2003). Localizando ciudades en circuitos globales. EURE, 29(88), 5-27. En http:// www.eure.cl/index.php/eure/article/view/1289

Secretaría de Desarrollo Social, Consejo Nacional de Población \& Instituto Nacional de Estadística y Geografía (2012). Delimitación de las zonas metropolitanas de México 2010. México, D.F: Autores. En http://www.conapo.gob.mx/es/conapo/Zonas_ metropolitanas_2010

Singer, P. (1977). Economía política de la urbanización. México, D.F.: Siglo XxI.

Vidal-Koppmann, S. (2009). Fragmentación socio-espacial en la periferia de la Región Metropolitana de Buenos Aires. Journal of Latin American Geography, 8(1), 79-97. doi: 10.1353/lag.0.0038 
Yocelevzky, R. (1999). La relevancia de las contribuciones de Immanuel Wallerstein para las ciencias sociales latinoamericanas. En F. Baca \& B. Cisneros (Eds.), Los intelectuales $y$ los dilemas politicos en el siglo XX (Tomo I, pp. 215-233). México, D.F.: Universidad Autónoma Metropolitana-Xochimilco. 